\title{
Organizational Culture and Knowledge Exchange and Combination: A Systematic Literature Review
}

\author{
Désirée Laubengaier \\ German Graduate School of \\ Management and Law, Germany \\ desiree.laubengaier@ggs.de
}

\author{
Gerd J. Hahn \\ German Graduate School of \\ Management and Law, Germany \\ gerd.hahn@ggs.de
}

\author{
Heinz-Theo Wagner \\ German Graduate School of \\ Management and Law, Germany \\ heinz-theo.wagner@ggs.de
}

\begin{abstract}
Knowledge exchange and combination build the core of innovative activity. Organizational culture plays a critical role with regards to knowledge exchange and combination because it affects organization members' behaviors. Thus, his study aims at analyzing the influence of organizational culture on knowledge exchange and combination. Based on a systematic literature review, this study takes stock of the landscape of research on organizational culture related to knowledge exchange and combination. 504 journals and 5 conference proceedings were examined. 24 articles were identified as relevant and were reviewed. We found that organizational culture is a strong predictor for successful knowledge exchange and combination. The analysis further revealed four cultural factors that were mentioned most frequently as being supportive of knowledge exchange and combination. Our literature review points out the lack of research on how to develop, change, and sustainably establish an organizational culture that exhibits the corresponding supportive factors.
\end{abstract}

\section{Introduction}

Organizational culture gains a lot of interest in practice and academia alike and plays a crucial role for organizations. Organizational culture represents "a complex set of values, beliefs, assumptions, and symbols that define the way in which a firm conducts its business" $[60,66]$. Organizational culture is shared among organization members [29] and determines their behaviors as well as attitudes $[60,66]$. Influence occurs through shared values, beliefs, norms, and expectations [33]. These collectively shared aspects can also affect employees' knowledge exchange and combination activities [20]. Organizational culture implicitly guides organization members' actions and behaviors so that these are typically executed in a subconscious manner
[28]. Within the organizational culture, it is embedded which behaviors are desired and expected from the organization members. As a result, organizational culture directs members' behaviors at least in a subtle manner [60]. Organizational culture has attained great attention in the context of superior organizational performance (e.g. [25, 57, 72]). Further, it has been largely discussed as a source of sustainable competitive advantage (e.g. $[8,26])$, and, commonly, culture serves as an explanatory factor for various organizational outcomes. The link to effectiveness, for example, is well established [26, 72]. Also, organizational culture has been researched in regards to employee-related aspects such as motivation, creativity, and other jobrelated variables like job satisfaction (e.g. [41]).

An aspect that is closely related to an organization's functioning and competitiveness is innovation [7]. Consequently, innovation increasingly plays a major role in organizations. Accordingly, extant literature deals with the antecedents of innovation, and organization scholars increasingly stress organizational culture's influence on innovation [14, 37, 37, 40, 46, 67]. From a knowledge-based perspective, innovation refers to the "creation and application of knowledge to create new knowledge regarding novel products and processes" [65]. Innovation and knowledge are, thus, closely related concepts and knowledge can be regarded as a critical firm resource [32] because it enables and drives innovation success [68]. New knowledge is a prerequisite for innovation, and the creation of new knowledge warrants the exchange and combination of knowledge [42, 64]. Consequently, knowledge creation can be considered the "precursor of innovation" [64], and for generating innovation the processes of knowledge exchange and combination are essential [50, 63]. Correspondingly, literature considers factors that influence knowledge exchange as well as knowledge combination and studies propose a plethora of such factors. Among those factors, culture gains specific attention because it either supports or inhibits knowledge management practices [1]. An 
organizational entity that not only contains knowledge but also influences its treatment within an organization, is organizational culture [2]. It is less about the existence of knowledge but rather about the ability of an organization to effectively put knowledge into use and exchange and recombine it successfully, which in turn serves as the basis for sustainable competitive advantage [2].

Considering the important role of knowledge exchange and combination, extant literature deals with topics around the broad subject of knowledge management (e.g. [2, 9, 13]). A large body of research has discussed on possible relations between organizational culture and knowledge-related subjects. Various studies have pointed out organizational culture as being a significant challenge or barrier for knowledge management (e.g. [1, 6, 48]). Others have stressed that organizational culture could be conducive to knowledge management (e.g. [24, 49, 56]). Also, organizational culture has been identified as an antecedent for many knowledge-related concepts (e.g., $[45,58])$. Great efforts have been made with regards to knowledge management practices (e.g. [21, 55]), so that the relationship between knowledge management practices and organizational culture is well established $[1,10]$. Similarly, the impact of organizational culture on organizational learning has been disentangled (e.g. [58]). With regards to knowledge exchange and combination, the link to innovation is clearly confirmed (e.g. [64]), and social climates fostering knowledge exchange and combination have also attracted attention (e.g. [20]). Recently, a systematic literature on the relationship between organizational culture and knowledge management has been conducted by Müller [52]. However, this study omits knowledge exchange and combination.

Overall, a number of studies within various disciplines have examined how organizational cultural characteristics influence knowledge, knowledge management, and innovation. A diverse research base consisting of theoretical and empirical work has been accumulated. Based on the aforementioned literature, it becomes evident that literature synthesizing scattered research on the influence of organizational culture and innovation from a knowledge-based perspective, hence paying attention to knowledge exchange and combination, is scant. No systematic literature analysis that follows a comprehensive approach and focuses on organizational culture's influence on knowledge exchange and combination has been conducted.

Considering the issues above, this paper consolidates relevant empirical literature on organizational culture's influence on knowledge exchange and combination, and brings together findings from culture and knowledge literature.
Thereby, we aim at answering the following research question: How is organizational culture related to knowledge exchange and combination?

Drawing on social capital theory [53], we conduct a structured and systematic analysis of literature that empirically investigates organizational culture's influence on knowledge exchange and knowledge combination. By doing so, we contribute to existing innovation and culture literature by investigating organizational culture as an antecedent to innovation from a knowledge-based perspective. As we approach innovation from a knowledge-based perspective, we take knowledge exchange and knowledge combination into account. We further contribute to research by offering a comprehensive literature review on the influence of organizational culture on knowledge exchange and combination which allows unifying findings from different strands of culture, knowledge, and innovation literature. Furthermore, it offers the opportunity to build a more thorough understanding of an organizational culture supportive to innovation by fostering knowledge exchange and combination.

The remainder of the paper is structured as follows. The upcoming section provides related literature on organizational culture and knowledge exchange and combination. In section 3, the research methodology is introduced. Subsequently, in section 4 we present the results and in section 5, we discuss the implications and point towards future research avenues. Finally, we elaborate this study's limitation.

\section{Related literature}

Considering our research question that concerns organizational culture and knowledge exchange and combination, the following two sections deal with the fundamentals of each of these topics. In section 2.1, we elucidate the concept of organizational culture. As we analyze organizational culture's influence on knowledge exchange and combination through the theoretical lens provided by social capital theory, we introduce its implications in section 2.2.

\subsection{Organizational culture}

Despite much research on organizational culture, there is still no common agreement on how to define this concept [8, 38] and literature provides various definitional approaches. In their early work, Kroeber and Kluckhohn [43] already identified 164 definitions of culture. Schein [59] states that the ambiguity of the organizational culture concept itself causes these definitional problems. Jaques [36], in his seminal work, applied the concept of culture to organizations 
and referred to the culture of a factory as " $(\ldots)$ its customary and traditional way of thinking and doing of things, which is shared (...) by all its members, and which new members must learn, and at least partially accept, in order to be accepted (...)" [36]. Derived from this understanding, organizational culture can be thought of as the "collective programming of the mind which distinguishes the members of one organization from another" [35]. In a more 'practical' way, organizational culture can be described as "the 'glue' that holds organizations together" [62]. Schein [59] defines organizational culture as "(a) a pattern of basic assumptions, (b) invented, discovered, or developed by a given group, (c) as it learns to cope with its problems of external adaptation and internal integration, (d) that has worked well enough to be considered valid and, therefore (e) is to be taught to new members as the (f) correct way to perceive, think, and feel in relation to those problems" [59]. Moreover, organizational culture manifests at different levels [61]. Relatively observable aspects to less observable, rather unconscious aspects together make up an organizational culture. Schein's widely accepted theoretical framework proposes that organizational culture consists of three interrelated levels: (1) observable artifacts (e.g. symbols, rituals or language), (2) values and norms of expected behaviors, and (3) underlying assumptions.

A concept closely related to organizational culture is organizational climate. Although there are "similarities, several reasons exist for viewing climate and culture as distinct" [44]. Climate is more specific and is concerned with individual perceptions [47]. Culture, on the contrary, is collectively shared among members and relates to patterns of behavior (e.g. [61]). For the purpose of our review, we acknowledge the relatedness of the concepts, but treat climate and culture as (related but) distinct constructs. Accordingly, we deliberately exclude organizational climate from our analysis. This approach is in line with the systematic literature reviews of Müller [52] and Leidner and Kayworth [47], who leave organizational climate in their studies around organizational culture aside.

\subsection{Knowledge exchange and combination}

Knowledge creation is often considered as a main driver for organizational innovation [64]. Schumpeter [63] argues that innovation, hence new knowledge, is created through the processes of knowledge exchange and combination. Knowledge represents "a high value form of information that is ready to apply to decisions and actions" [24]. In correspondence with the ideas of Schumpeter [63], social capital theory by Nahapiet and Ghoshal [53] posits that new knowledge is created through two generic processes: knowledge exchange and knowledge combination. Following existing research (e.g. [12, 64]), we apply this theoretical lens for our analysis. Consequently, we adopt Nahapiet and Ghoshal's [53] reasoning, and acknowledge that there might be other processes relevant for the creation of new knowledge, but we assume that exchange and combination of knowledge build the core of any innovative activity. Knowledge exchange represents "interchanging knowledge and information residing in different organizational members and subunits" [64]. Combination of "previously unconnected pieces of knowledge" [12] enables incremental innovation, whereas radical innovation emerges as a result of novel ways of combining elements that might have previously been associated [53]. Radical innovation is mostly associated with the application of new knowledge to develop completely new products, services or processes. Incremental innovation, on the other hand, is intertwined with the reconfiguration of existing knowledge to refine and improve existing products, services or processes [34]. According to social capital theory, there is an underlying relation between knowledge exchange and combination with knowledge exchange being the prerequisite for knowledge combination. This linkage results from the fact that knowledge can be located at myriad entities [12].

Apart from that, social capital theory brings up four conditions that need to be met for knowledge exchange and combination to occur in an organizational setting. The first condition asserts that an opportunity for exchange or combination exists. That is, knowledge to be combined must be available, as well as the opportunity and means for combining the knowledge. Second, the parties involved need to expect or conjecture some added-value regarding knowledge resulting from the exchange and combination. Third, motivation is highly important for considering and conducting exchange and combination. Even if the first and second conditions are met, the parties involved need to experience benefitting from engaging in exchange and combination, so that - even under uncertain results - participating represents an incentive $[51,53]$. The fourth condition is the capability to conduct knowledge combination. Opportunities for knowledge exchange and combination, the associated knowledge benefits, as well as the underlying motivation are altogether not sufficient - additionally, the capability to combine knowledge assets is indispensable [53].

Another crucial aspect of social capital theory is that social capital is influential in the creation of new knowledge. Social capital can facilitate knowledge exchange and combination by affecting the conditions 
previously discussed. Social capital refers to "the sum of the actual and potential resources embedded within, available through, and derived from the network of relationships possessed by an individual or social unit" [53]. Nahapiet and Ghoshal [53] distinguish three dimensions of social capital: the structural, the cognitive, and the relational dimension. The network of relations, meaning the "overall pattern of connections between actors" [53], constitutes the structural dimension. The cognitive dimension deals with shared cognition and sharing of context among organization members which come into effect through shared language, codes, and narratives. The relational dimension of social capital refers to "assets created and leveraged through relationships" [53]. 'Relational' resources originate from social interaction, and bond the members of a social system, such as an organization. Associated with this dimension are, therefore, norms which are important for knowledge exchange and combination.

For the purpose of our analysis, we focus on the relational dimension, specifically norms, and argue that there is a close link to the concept of organizational culture. We justify this by the fact that the relational dimension of social capital encompasses norms which are also a vital component of organizational culture.

Norms represent "a degree of consensus in the social system" [53] such as an organization. Norms are to be grasped as the collectively binding demands and expectations regarding the conduct within the social system. They give direction to behavior, and if effectively in use, norms have a powerful effect on organization members' conduct. Consequently, organization members' knowledge exchange and combination activities can be significantly affected by norms. Whether and to what extent the members engage in these knowledge creation processes largely depends on what kind of norms are embedded in the social context. Nahapiet and Ghoshal [53] point out norms that are proposed to build a "strong fundament" [53] for knowledge exchange and combination: norms of cooperation, openness and teamwork, appreciation of diversity, and tolerance of failure.

Thus far, we have argued that social capital theory provides a solid lens for analyzing organizational culture's influence on knowledge exchange and combination. In the next section, we illustrate the research approach which has been applied in alignment with our theoretical foundation.

\section{Research method}

A structured literature review was conducted on the basis of Webster and Watson [71], vom Brocke et al. [70], and Denyer and Tranfield [27]. This research method aims at a rigorous approach and maximum transparency with respect to the review process. In order to comply with this requirement, we followed Creswell [22] and executed the recommended steps:

1) "Identify the key terms to use in the research

2) Locate literature about a topic by consulting

several types of material and databases

3) Critically evaluate and select the literature for review

4) Organize the selected literature

5) Write a literature review that reports summaries of the literature" [22].

In the first step, central terms of our research question (organizational culture, knowledge exchange and combination) were used as key elements. We supplemented these with a few synonyms and related terms to broaden the search. In line with Müller [52], we deliberately excluded related concepts, such as climate and information, from our search in order to contain the scope of relevant literature. The resulting key terms for the literature search needed to be present in the abstract at least. Further, we applied two Boolean expressions (AND/OR) for combining the identified terms. As a result, the following search string was developed: $\mathrm{AB}$ ("corporate cultur*" OR "cultur*" OR "organi\#ation* cultur*") AND AB ("innovat*" OR "knowledge combination" OR "knowledge exchange") AND AB ("knowledge management"). Because knowledge combination and exchange are connected to knowledge management [12], we added the term 'knowledge management' to our search string. In doing so, we intend to ensure that literature with a knowledge-based perspective is being identified.

In order to foster rigor, we determined peerreviewed academic journals and conference publications as a basis to identify relevant literature for our review. This excludes practitioner articles, dissertations, and books. Refereed journals provide a level of quality control, and the conference proceedings we selected are acknowledged in the field of IS.

The journal rankings 'Association of Business Schools Academic Journal Quality 2015' (ABS), 'VHB-JOURQUAL 3' (VHB), and 'ESSEC Business School Paris 2016' (ESSEC) served as sources for selecting journals. Concerning ABS, we defined the rankings $4 *$ ("world elite journal") up to and including 1 ("recognised journal") being notable. For VHB we chose the ranges from A+ ("world leading") up to and 
including C ("recognised"). For ESSEC, we considered the rankings $0+$ ("recognised internationally as the best in the discipline") up to and including 2 ("generally national-circulation journals, or international journals of lesser reputation"). Due to the fact that an unstructured pre-search - which was conducted to obtain a rough overview - located relevant literature in journals classified as mediocre, we applied this wide scope ranging from highest-quality to well-recognized. We selected journals from diverse disciplines such as information systems, knowledge management, entrepreneurship, technology, innovation, general and strategic management, organization behavior, sociology, human resources, marketing, psychology, logistics and productions, and others to take care of the interdisciplinarity of the topic. Our journal list finally consisted of 504 journals. Additionally, the following 5 conference proceedings were included: Proceedings of the European Conference on Information Systems (ECIS), Proceedings of the Hawaii International Conference on System Sciences (HICSS), Proceedings of the International Conference on Information Systems (ICIS), Proceedings of the Internationale Tagung Wirtschaftsinformatik (WI), and Proceedings of the Pacific Asia Conference on Information Systems (PACIS).

To ensure a rigorous and systematic search [71], the search string was applied using a meta-search engine (based on 202 different databases, such as EBSCO Business Source Complete), which consisted of the previously defined journals and conference proceedings. The search process returned 103 relevant research articles. To extract relevant literature out of the results, we conducted a filtering process based on the following criteria: (1) Studies treat culture as an antecedent for knowledge-related subjects. (2) Research needed to be empirical which excludes other types of research such as conceptual, descriptive or anecdotal studies. The final sample to be examined then constituted 24 articles.

\section{Analysis and findings}

In the following, we first discuss organizational culture and, then, turn to the results regarding the influence organizational culture exerts on knowledge exchange and combination.

\subsection{Organizational culture: conceptualization and approaches}

Literature provides a variety of conceptualizations of organizational culture, and there is no agreement on how culture should be conceptualized [39]. Our review revealed that quantitative studies mostly apply an either dimensional or typological approach.

With regards to typologies, most frequently the Competing Values Framework, which proposes different types of organizational culture, is used. Clan, adhocracy, market, and hierarchy culture are the most frequently considered culture types (e.g. [69]). Commonly, adhocracy culture receives attention as the culture type that significantly encourages knowledge exchange and combination (e.g. [16]).

Dimensional approaches mainly draw on cultural values that are supposed to be associated with knowledge exchange and combination [15, 17]. Brockman [11], for example, draws on the cultural value of entrepreneurship and finds evidence for a positive association to the exchange of new knowledge.

\subsection{Organizational culture's influence on knowledge exchange and combination}

In order to gain a comprehensive understanding of how organizational culture relates to knowledge exchange and combination, the influences proposed by the articles we analyzed were extracted. All research articles emphasize organizational culture being utmost important for knowledge-related activities within an organization. Studies consistently argue that organizational culture can basically encompass two directions of effects on knowledge exchange and combination. Organizational culture can either support or impede knowledge exchange and combination (e.g. $[23,69])$. Chatzoudes, for example, provide empirical evidence for organizational culture being the antecedent with the strongest impact on the knowledge management process [17]. Cultural aspects such as values and norms 'environ' the organization members and have the power to shape their behaviors to a significant extent. Members' knowledge exchange and combination practices largely depend on the contents incorporated in the organizational culture. Only an organizational culture that truly values knowledge exchange and combination can get the members there [5]. In order to achieve such a culture which positively affects and encourages members to engage in knowledge exchange and combination, the corresponding behavioral aspects need to be embedded in the organizational culture.

Studies propose a plethora of cultural factors that are found to support knowledge exchange and combination. We gathered the factors most frequently referred to and identified 4 categories. Therefore, we subsequently organize the findings along these 4 categories of organizational cultural aspects that were 
found to support knowledge exchange and combination.

4.2.1. Risk-taking. One of the most frequently stated factors is risk-taking, which is also referred to as tolerance of risk (e.g. [11, 15, 17, 18, 30]). Risk-taking describes the willingness to venture and consequently tolerate mistakes and failure. Accordingly, risk-taking reduces members' aversion of uncertainty and enhances coping with unfamiliar situations (e.g. [3, 15]). Trying new "ways of doing things" [3] is typically a risky endeavor, and may lead to unexpected outcomes. Gonzales and Melo [31], for example, find that the posture towards taking risk and making decisions largely determines the success of knowledge management practices.

4.2.2. Openness. Openness represents a cultural aspect that is proposed to positively influence knowledge management behaviors (e.g. [3, 15]). Albert and Picq [3], for instance, find that open communication is important for the creation of knowledge. Organization members should be encouraged with regards to open discussion and discourse. Communicational exchange, such as feedback, can foster open communication. In this study, it is also found that openness among organization members contributes to the change of cultural norms [3]. Particularly, for the exchange of knowledge, continuous openness plays a crucial role [15]. Argued from another perspective, beyond and across organization boundaries, openness and sharing of knowledge becomes relevant [4]. Experimentation and freedom are cultural aspects [16] that we organized into the category of openness since openness can be considered as a precondition for both acting freely as well as for experimenting. It is also found that the realization of knowledge management requires that organization members exhibit an open mindset which incorporates not only being open to changing processes but also to adopting new knowledge [4]. Yang, Marlow, and Lu [73], for instance, find that exploration and experimenting are one of the most important attributes of a culture that is supportive of knowledge exchange and combination.

4.2.3. Flexibility. Another frequently mentioned cultural aspect that is required for successful exchange and combination of knowledge and thus innovation, is flexibility (e.g. [11, 17, 19]. Many studies find evidence that an organizational culture which incorporates flexibility is positively associated to knowledge-related subjects, such as knowledge creation (e.g. [17]) or knowledge management processes (e.g. [15]). Additionally, some research equates flexibility with adaptability (e.g. [16]). Other studies examine the influence of flexibility on knowledge-activity from a structural perspective (e.g. [19]).

4.2.4. Future orientation. Cultural content that is frequently associated with a positive effect on knowledge-related activities is future orientation (e.g. $[11,15])$. Future orientation is defined as the "degree to which individuals in organizations or societies engage in future-oriented behaviors such as planning, investing in the future, and delaying individual or collective gratification" [54]. Closely related to future orientation is a strong focus on customers. Chen and Hatzakis [18] stress that a consistent customer orientation is accompanied by the creation of new knowledge with regards to customers' concerns. As the "aim is to deploy knowledge (...) for the benefit of the customer", it is necessary to pursue this long-term view which in turn supports knowledge creation. Organizations need to be proactive when they are competing with other organizations. Pursuing new market opportunities as well as renewing new knowledge are essential for organizations to effectively operate [11].

\section{Organizational Knowledge culture creation}

\begin{tabular}{|c|c|}
\hline $\begin{array}{ll}\text { - } & \text { Risk-taking } \\
\text { - } & \text { Openness } \\
\text { - } & \text { Flexibility } \\
\text { - } & \text { Future } \\
& \text { orientation }\end{array}$ & $\begin{array}{l}\text { - Knowledge } \\
\text { exchange } \\
-\quad \begin{array}{l}\text { Knowledge } \\
\text { combination }\end{array}\end{array}$ \\
\hline
\end{tabular}

Figure 1. Frame and results of the systematic literature review

\section{Discussion}

In our study, we conducted a structured literature review on the influence of organizational culture on knowledge exchange and combination. Thereby, we asked the following research question: How is organizational culture related to knowledge exchange and combination?

The brief answer we found is that organizational culture largely influences the occurrence of knowledge exchange and combination in organizations. As knowledge exchange and combination are the underlying processes of knowledge creation, 
respectively innovation, this finding highlights the importance of organizational culture.

The results indicate that organizational culture is strongly related to knowledge exchange and combination. Depending on the factors incorporated in the organizational culture, an either positive or negative effect can be observed. With this review, we identified organizational cultural aspects that are positively associated with knowledge exchange and combination. Accordingly, we consolidated cultural factors that literature proposes to positively influence knowledge exchange and combination. During the review, four cultural factors were found to be mainly referred to in the articles. Thus, we decided to organize our findings according to these categories. We found risk-taking, openness, flexibility, and future orientation to be mostly associated with knowledge exchange and combination. In conclusion, we contribute to research by the identification of these 4 cultural aspects that were found to facilitate knowledge exchange and combination. Based on this comprehensive collection of supportive aspects of organizational culture, attempts of organizations to developing and changing an organizational culture towards a 'knowledge culture' can be conducted more goal-oriented.

However, our summary indicates a lack of research in terms of how to change and how to develop an organizational culture. Cultural change is a major challenge for organizations. Nevertheless, nowadays, it becomes increasingly important. Consequently, future research should explore this area and provide more thorough approaches for changing and developing organizational culture successfully.

\section{Limitations of the literature review}

Although this literature review provides valuable insights on the influence of organizational culture on knowledge exchange and combination, some limitations need to be considered. First, the results of this review are restricted by the approach for the literature selection, as the review is based on peerreviewed journals and conference proceedings only. Although our publication base is of high quality, some relevant contributions may be missing, since we excluded non-peer-reviewed work. Second, the search and selection approach further limits the findings. As our search terms are limited to English, literature of other languages is disregarded. Also, the search string could have led to an exclusion of relevant research, as further potentially related terms might have been omitted. Third, this research considers organizational culture only. Related concepts such as organizational climate could help shedding light on the contextual factors influencing the knowledge exchange and combination in organizational settings. Finally, cultural factors inhibiting knowledge exchange and combination were not examined in this review. Future research needs to consolidate aspects of organizational cultures that negatively affect knowledge exchange and combination. This would help elucidate the complex relationship between organizational culture and knowledge exchange and combination.

\section{References}

[1] M. Alavi, T.R. Kayworth, and D.E. Leidner, "An Empirical Examination of the Influence of Organizational Culture on Knowledge Management Practices", Journal of Management Information Systems, 22(3), 2005, pp. 191-224.

[2] M. Alavi and D.E. Leidner, "Review: Knowledge Management and Knowledge Management Systems: Conceptual Foundations and Research Issues", MIS Quarterly, 25(1), 2001, pp. 107-136.

[3] M. Albert and T. Picq, "Knowledge-based Organizations: Perspectives from San Francisco Bay Area Companies", European Journal of Innovation Management, 7(3), 2004, p. 169.

[4] T.C. Ambos and B.B. Schlegelmilch, "Managing Knowledge in International Consulting Firms", Journal of Knowledge Management, 13(6), 2009, p. 491.

[5] F.M.R. Armbrecht, JR., R.B. Chapas, C.C. Chappelow, G.F. Farris, P.N. Friga, C.A. Hartz, M.E. McIlvaine, S.R. Postle, and G.E. Whitwell, "Knowledge Management in Research and Development", Research Technology Management, 44(4), 2001, pp. 28-48.

[6] J. Auernhammer and H. Hall, "Organizational Culture in Knowledge Creation, Creativity and Innovation: Towards the Freiraum Model", Journal of Information Science, 40(2), 2013, pp. 154-166.

[7] M. Baer, "Putting Creativity to Work: The Implementation of Creative Ideas in Organizations", Academy of Management Journal, 55(5), 2012, pp. 11021119.

[8] J.B. Barney, "Organizational Culture: Can It Be a Source of Sustained Competitive Advantage?", The Academy of Management Review, 11(3), 1986, pp. 656-665.

[9] A. Bennet and D. Bennet, "The Partnership between Organizational Learning and Knowledge Management", in Handbook on Knowledge Management 1: Knowledge Matters, C.W. Holsapple, Editor. 2004. Springer: Berlin, Heidelberg. 
[10] M. Birasnav, A. Goel, and R. Rastogi, "Leadership Behaviors, Organizational Culture, and Knowledge

Management Practices: An Empirical Investigation", Amity

Global Business Review, 7, 2012, pp. 7-13.

[11] B.K. Brockman and R.M. Morgan, "The Role of Existing Knowledge in New Product Innovativeness and Performance", Decision Sciences, 34(2), 2003, p. 385.

[12] A. Cabrera and E.F. Cabrera, "Knowledge-Sharing Dilemmas", Organization Studies, 23(5), 2002, pp. 687-710.

[13] D.I. Castaneda, L.F. Manrique, and S. Cuellar, "Is Organizational Learning Being Absorbed by Knowledge Management? A Systematic Review", Journal of Knowledge Management, 22(2), 2018, pp. 299-325.

[14] G.N. Chandler, C. Keller, and D.W. Lyon, "Unraveling the Determinants and Consequences of an InnovationSupportive Organizational Culture", Entrepreneurship Theory and Practice, 25(1), 2000, pp. 59-76.

[15] C.L. Chang and T.-C. Lin, "The Role of Organizational Culture in the Knowledge Management Process", Journal of Knowledge Management, 19(3), 2015, pp. 433-455.

[16] P. Chatzoglou and D. Chatzoudes, "The Role of Innovation in Building Competitive Advantages: An Empirical Investigation", European Journal of Innovation Management, 21(1), 2018, pp. 44-69.

[17] D. Chatzoudes, P. Chatzoglou, and E. Vraimaki, "The Central Role of Knowledge Management in Business Operations: Developing a New Conceptual Framework", Business Process Management Journal, 21(5), 2015, pp. 1117-1139.

[18] W. Chen and T. Hatzakis, "Knowledge Management, Absorptive Capacity and Organisational Culture: A Case Study from Chinese SMEs", International Journal of Knowledge Management Studies, 2(3), 2008, 371-381.

[19] Chen. T. Fue, "Transforming Knowledge into Action to Reach Innovation Capacity in High-Tech SMEs", International Journal of Innovation \& Technology Management, 9(1), 2012, 1250005-1.

[20] C.J. Collins and K.G. Smith, "Knowledge Exchange and Combination: The Role of Human Resource Practices in the Performance of High-Technology Firms", Academy of Management Journal, 49(3), 2006, pp. 544-560.

[21] R. Coombs and R. Hull, "Knowledge Management Practices and Path-Dependency in Innovation", Research Policy, 27(3), 1998, pp. 237-253.

[22] J.W. Creswell, Educational Research: Planning, Conducting, and Evaluating Quantitative and Qualitative
Research, 4th edn., Upper Saddle River: Pearson Education, 2011.

[23] L. Damodaran and W. Olphert, "Barriers and Facilitators to the Use of Knowledge Management Systems", Behaviour \& Information Technology, 19(6), 2000, pp. 405-413.

[24] T.H. Davenport, D.W. de Long, and M.C. Beers, "Successful Knowledge Management Projects", Sloan Management Review, 39(2), 1998, pp. 43-58.

[25] T.E. Deal, A.A. Kennedy, and G.F. Doriot, Corporate Cultures: The Rites and Rituals of Corporate Life, Reading, Mass. : Addison-Wesley Pub. Co., 1982.

[26] D.R. Denison and A.K. Mishra, "Toward a Theory of Organizational Culture and Effectiveness", Organization Science, 6(2), 1995, pp. 204-223.

[27] D. Denyer and D. Tranfield, "Producing a Systematic Review", in The Sage handbook of organizational research methods. 2009.

[28] S. Giorgi, C. Lockwood, and M.A. Glynn, "The Many Faces of Culture: Making Sense of 30 Years of Research on Culture in Organization Studies", The Academy of Management Annals, 9(1), 2015, pp. 1-54.

[29] C. Glisson and L.R. James, "The Cross-Level Effects of Culture and Climate in Human Service Teams", Journal of Organizational Behavior, 23(6), 2002, pp. 767-794.

[30] R.V.D. Gonzalez and M.F. Martins, "Mapping the Organizational Factors that Support Knowledge Management in the Brazilian Automotive Industry", Journal of Knowledge Management, 18(1), 2014, pp. 152-176.

[31] R.V.D. Gonzalez and T.M. Melo, "Linkage between Dynamics Capability and Knowledge Management Factors", Management Decision, 55(10), 2017, p. 2256.

[32] R.M. Grant, "Toward a Knowledge-Based Theory of the Firm", Strategic Management Journal, 17, 1996, pp. 109-122.

[33] C.A. Hartnell, A.Y. Ou, and A. Kinicki, "Organizational culture and organizational effectiveness: A meta-analytic investigation of the competing values framework's theoretical suppositions", The Journal of applied psychology, 96(4), 2011, pp. 677-694.

[34] R.M. Henderson and K.B. Clark, "Architectural Innovation: The Reconfiguration of Existing Product Technologies and the Failure of Established Firms", Administrative Science Quarterly, 35(1), 1990, pp. 9-30.

[35] G.H. Hofstede, Cultures and Organizations: Software of the Mind, London; New York: McGraw-Hill, 1991. 
[36] E.L. Jaques, The Changing Culture of a Factory, Dryden Press, London, 1951.

[37] A.R. Jassawalla and H.C. Sashittal, "Cultures That Support Product-Innovation Processes", Academy of Management Executive, 16(3), 2002, pp. 42-54.

[38] R.A. Jones, N.L. Jimmieson, and A. Griffiths, "The Impact of Organizational Culture and Reshaping Capabilities on Change Implementation Success: The Mediating Role of Readiness for Change", Journal of Management Studies(2), 2005 , p. 361.

[39] T. Jung, T. Scott, H.T.O. Davies, P. Bower, D. Whalley, R. McNally, and R. Mannion, "Instruments for Exploring Organizational Culture: A Review of the Literature", Public Administration Review, 69(6), 2009, pp. 1087-1096.

[40] S. Khazanchi, M.W. Lewis, and K.K. Boyer, "Innovation-supportive Culture: The Impact of Organizational Values on Process Innovation", Journal of Operations Management, 25(4), 2007, pp. 871-884.

[41] C.S. Koberg and L.H. Chusmir, "Organizational Culture Relationships with Creativity and Other Job-Related Variables", Journal of Business Research, 15(5), 1987, pp. 397-409.

[42] B. Kogut and U. Zander, "Knowledge of the Firm, Combinative Capabilities, and the Replication of Technology", Organization Science, 3(3), 1992, pp. 383-397.

[43] A.L. Kroeber and C. Kluckhohn, Culture: A Critical Review of Concepts and Definitions, The Museum, Cambridge, Mass., 1952.

[44] M. Kuenzi and M. Schminke, "Assembling Fragments Into a Lens: A Review, Critique, and Proposed Research Agenda for the Organizational Work Climate Literature", Journal of Management, 35(3), 2009, pp. 634-717.

[45] D.A. Ladd and A.R. Heminger, "An Investigation of Organizational Culture Factors That May Influence Knowledge Transfer", 2003.

[46] K. Lee, H.-G. Woo, and K. Joshi, "Pro-Innovation Culture, Ambidexterity and New Product Development Performance: Polynomial Regression and Response Surface Analysis", European Management Journal, 35(2), 2017, pp. 249-260.

[47] D.E. Leidner and T. Kayworth, "Review: A Review of Culture in Information Systems Research: Toward a Theory of Information Technology Culture Conflict", MIS Quarterly, 30(2), 2006, pp. 357-399.

[48] D.W. de Long and L. Fahey, "Diagnosing Cultural Barriers to Knowledge Management", Academy of Management Executive(4), 2000, p. 113.
[49] R. McDermott and C. O’Dell, "Overcoming Cultural Barriers to Sharing Knowledge", Journal of Knowledge Management, 5(1), 2001, pp. 76-85.

[50] B. Moos, D. Beimborn, H.-T. Wagner, and T. Weitzel, "The Role of Knowledge Management Systems for Innovation: An Absorptive Capacity Perspective", International Journal of Innovation Management(5), 2013, p. 1350019.

[51] P. Moran and S. Ghoshal, "Value Creation by Firms", Academy of Management, 1996.

[52] J. Mueller, "The Interactive Relationship of Corporate Culture and Knowledge Management: A Review", Review of Managerial Science, 6(2), 2012, pp. 183-201.

[53] J. Nahapiet and S. Ghoshal, "Social Capital, Intellectual Capital, and the Organizational Advantage", The Academy of Management Review, 23(2), 1998, pp. 242-266.

[54] M. Naor, K. Linderman, and R. Schroeder, "The Globalization of Operations in Eastern and Western countries: Unpacking the Relationship between National and Organizational Culture and its Impact on Manufacturing Performance", Journal of Operations Management, 28(3), 2010, pp. 194-205.

[55] H.N. Nguyen and S. Mohamed, "Leadership Behaviors, Organizational Culture and Knowledge Management Practices: An Empirical Investigation", Journal of Management Development(2), 2011, p. 206.

[56] S. Oliver and K.R. Kandadi, "How to Develop Knowledge Culture in Organizations?: A Multiple Case Study of Large Distributed Organizations", Journal of Knowledge Management, 10(4), 2006, pp. 6-24.

[57] T.J. Peters and R.H. Waterman, In Search of Excellence: Lessons from America's Best-Run Companies, London : Profile Books, 2004, 2004.

[58] R. Sanz-Valle, J.C. Naranjo-Valencia, D. JimenezJimenez, and L. Perez-Caballero, "Linking Organizational Learning with Technical Innovation and Organizational Culture", Journal of Knowledge Management, 15(6), 2011, pp. 997-1015.

[59] E.H. Schein, "Organizational Culture", American Psychologist, 45(2), 1990, pp. 109-119.

[60] E.H. Schein, Organizational Culture and Leadership, San Francisco: Jossey-Bass, 1992.

[61] E.H. Schein, Organizational Culture and Leadership, San Francisco : Jossey-Bass, 2010. 
[62] S.C. Schneider, "National vs. Corporate Culture: Implications for Human Resource Management", Human Resource Management, 27(2), 1988, pp. 231-246.

[63] J.A. Schumpeter, Theory of Economic Development, Transaction, Cambridge, MA, 1934.

[64] C. Shu, A.L. Page, S. Gao, and X. Jiang, "Managerial Ties and Firm Innovation: Is Knowledge Creation a Missing Link?", Journal of Product Innovation Management, 29(1), 2012, pp. 125-143.

[65] M. Shujahat, M.J. Sousa, S. Hussain, F. Nawaz, M. Wang, and M. Umer, "Translating the Impact of Knowledge Management Processes into Knowledge-Based innovation: The Neglected and Mediating Role of Knowledge-Worker Productivity", Journal of Business Research, 2018.

[66] L. Smircich, "Concepts of Culture and Organizational Analysis", Administrative Science Quarterly, 28(3), 1983, pp. 339-358.

[67] R. Stock, B. Six, and N. Zacharias, "Linking Multiple Layers of Innovation-Oriented Corporate Culture, Poduct Program Innovativeness, and Business Performance: A Contingency Approach", Journal of the Academy of Marketing Science, 41(3), 2013, pp. 283-299.
[68] M. Subramaniam and M.A. Youndt, "The Influence of Intellectual Capital on the Types of Innovative Capabilities", Academy of Management Journal, 48(3), 2005, pp. 450-463.

[69] S.-M. Tseng, "The Correlation between Organizational Culture and Knowledge Conversion on Corporate Performance", Journal of Knowledge Management, 14(2), 2010, pp. 269-284.

[70] J. Vom Brocke, A. Simons, B. Niehaves, K. Reimer, R. Plattfaut, and A. Cleven, "Reconstructing the Giant: On the Importance of Rigor in Documenting the Literature Search Process", 17th European Conference on Information Systems, 2009, pp. 2206-2217.

[71] J. Webster and R.T. Watson, "Analyzing the Past to Prepare for the Future: Writing a Literature Review", MIS Quarterly, 26(2), 2002, xiii-xxiii.

[72] A.L. Wilkins and W.G. Ouchi, "Efficient Cultures: Exploring the Relationship Between Culture and Organizational Performance", Administrative Science Quarterly(3), 1983, p. 468.

[73] C.-C. Yang, P.B. Marlow, and C.-S. Lu, "Knowledge Management Enablers in Liner Shipping", Transportation Research Part E, 45, 2009, pp. 893-903. 